\title{
Consumption and Environmental Awareness: Demographics of the European Experience
}

\author{
Philip S. Morrison and Ben Beer
}

\begin{abstract}
Who are the most pro-environmental in their purchasing behaviour? Is it the young, middle-aged or older consumers? The answer to this question has important implications for the marketing of pro-environmental products.

Our analysis of the Flash Eurobarometer Survey No. 256 released in 2009 reveals that it is not the young nor the very old, but the middle-aged buyers who are the most environmentally conscious. The relationship of environmental awareness and age takes an inverse $U$ shape: awareness rises with age, reaches a peak in early to late middle age and then declines with the oldest age groups. Middle-aged consumers are more likely to declare knowledge of the environmental impact of the products they buy and are most likely to appreciate the importance of the environmental consequences of their purchases. They are also the most likely to support ecolabelling and to the mandatory labelling of carbon footprints. At the same time, the magnitude of the difference between ages varies depending on which measure of environmental awareness is being considered.

The non-linear association between pro-environmental awareness and consumers' age holds even after controlling for gender, education, occupation and size of settlement. Although levels of environmental consciousness and age profiles vary across the countries of Europe, the greater awareness of the middle-aged consumer is sustained when we control for country.
\end{abstract}

Keywords Environmental awareness - Sustainable consumption - Pro-environmental $\bullet$ Demographics $\bullet$ Eco-labelling $\bullet$ Economic footprint $\bullet$ Europe

\section{Introduction}

In a globalised world complete with online shopping and express delivery service, consumption occurs on enormous scales, covers vast distances and supports everincreasing demand for the latest and greatest products (Robins 1999). Research into

P.S. Morrison $(\bowtie) \cdot$ B. Beer

Victoria University of Wellington, P.O. 600, Wellington, New Zealand

e-mail: Philip.morrison@vuw.ac.nz; Benybeer@gmail.com 
the adverse effect human consumption has on the environment accompanied these developments. The aim of our chapter is to identify patterns of pro-environmental consciousness among European residents. Our contribution lies in highlighting the middle-aged consumer as the most environmentally conscious in contrast to the young to whom such attitudes are often attributed.

During the 1992 Earth Summit, it was acknowledged that 'the major cause of the continued deterioration of the global environment is the unsustainable pattern of consumption and production, particularly in the industrialised countries' (UNCED 1992, cited by Robins 1999). In the last half-century, the world has experienced a rapid increase in the level of consumption. From the period 1960 to 1998, global consumption quadrupled (Robins 1999) and shows no sign of slowing down. The way in which the world's natural resources are being extracted to support the consumer industry is not sustainable over the long term, and it is estimated that with current consumption levels in Western society alone, we would require the equivalent of three earth planets to continue to facilitate this lifestyle (Carlisle and Hanlon 2007).

According to research done by Schor (2005), the world passed the point of sustainability in 1978. Succinctly described, '... "reckless consumption" of planetary resources has led to, among other things, accelerated rates of climate change, air and water pollution, deforestation, soil degradation and species loss' (Soron 2010: p. 172). Even economists, notorious for turning a blind eye to natural resource depletion, have begun to recognise the unsustainable nature of today's consumption (Carlisle and Hanlon 2007). There is a growing awareness of the need to address our consumption habits as a necessary course of action to reduce the drivers of environmental degradation.

Over the last 40 years, there has been some degree of success in creating increased demand for environmentally friendly products. Recognition of environmental impact has created a niche consumer market referred to commonly as 'green consumers'. The term 'green' is interchangeable with 'pro-environmental' and is broadly defined as indicating 'concern with the physical environment (air, water, land)' (Shrum et al. 1995: p. 72). Green consumption involves choosing goods that have minimal adverse impact on the natural environment. 'Eco-friendly' products are defined as '. . . ecologically safe products that can facilitate the long term goal of protecting and preserving our natural habitat' (Datta 2011: p. 126). Research into consumer trends relating to the production and marketing of green products has 'sought to identify and analyse green consumption values, attitudes and behaviours as well as explore ways to segment and target green consumers' (Schaefer and Crane 2005: p. 79). Identifying the characteristics, or profile, of the green consumer is a much coveted goal that has given rise to numerous articles (e.g. Jain and Kaur 2004, 2008).

A common finding has been the failure of demographic variables to provide consistent results (Straughan and Roberts 1999; Shrum et al. 1995; Peattie 2001). Some studies found green consumers to be older (e.g. Balderjahn 1988; Samdhal and Robertson 1989; Scott and Willits 1994; Roberts 1996b; Gilg et al. 2005), while other studies found them to be younger (e.g. Anderson and Cunningham 
1972; Tognacci et al. 1972; Van Liere and Dunlap 1980; Zimmer et al. 1994; Diamantopoulos et al. 2003). Most studies find that higher educated persons are greener (e.g. Van Liere and Dunlap 1980; Arcury and Christianson 1990; Roper Organization 1992; Jain and Kaur 2008); however, some surveys reveal no relationship or inconclusive results (e.g. Shrum et al. 1995; Laroche et al. 2001; Pepper et al. 2009; Abeliotis et al. 2010). At best the evidence suggests that the relationship between demographic variables and pro-environmental consciousness (or concern) is a complex one. As a result, some authors have concluded that in order to effectively establish the green consumer profile, attitudinal variables are a more reliable than demographic ones (e.g. Straughan and Roberts 1999; Laroche et al. 2001; Shrum et al. 1995; Roberts 1996b; Balderjahn 1988).

Nevertheless, demographic characteristics continue to be frequently used to profile the green consumer (Jain and Kaur 2008). It is a method that is still favoured by many researchers - especially market research companies who can more easily target demographic segments than groups of people divided along attitudinal lines (Peattie 2001; Roberts 1996b). One summary concluded that 'demographic analysis is useful in three ways: it can be used in trend analysis, used as market segment descriptors and it can also provide helpful information for policy questions related to macro marketing' (D'Souza et al. 2007: p. 372). The ability to identify trends between demographic variables and pro-environmental purchase behaviour will therefore greatly assist various businesses. As an example, Saphores et al. (2007) found age, income and education to be good indicators of willingness to pay more for 'green' electronics in California. Zarnikau (2003) uses the same variables to find correlations in willingness to pay more for sustainable energy products.

The illusive search for the profile of the green consumer continues after four decades of research. US-based researchers, Berkowitz and Lutterman (1968), Anderson and Cunningham (1972) as well as Webster (1975), were some of the first to conduct analysis in this field. Berkowitz and Lutterman (1968) concluded that a socially conscious consumer is likely to be a young female, highly educated and of a higher socio-economic status. Both Anderson and Cunningham (1972) and Webster (1975) drew similar conclusions. Studies continue to the present day and now cover many countries with little prior research in this area (e.g. Bodur and Sarigollu 2005 (Turkey); Sinnappan and Rahman 2011 (Malaysia); Abeliotis et al. 2010 (Greece) and Alibeli and Johnson 2009 (Middle East)). ${ }^{1}$

The rest of this chapter contains Sects. 2, 3, 4, 5, and 6. Section 2 offers a brief review of an extensive literature. Section 3 introduces the European Flash Barometer Survey that forms the empirical base for our enquiry. Section 4 outlines our methodology which involves post-estimating probabilities of responses to four different questions about consumers' environmental awareness. Levels of environmental awareness are expressed as a function of the respondent's age, while

\footnotetext{
${ }^{1} \mathrm{~A}$ full list of studies organised by publication date may be found in Beer (2013) which is available online: http://researcharchive.vuw.ac.nz/xmlui/bitstream/handle/10063/2646/thesis.pdf? sequence $=2$
} 
controlling for gender, education, occupation, settlement type and country. The core of the paper is in Sect. 5 where we assess the role of consumers' age in answering the four questions: how much they know about the products they buy, the importance they attach to the product's impact on the environment, the degree to which ecolabelling plays a role in their purchasing decision and how strongly they feel about whether the carbon footprint labelling of a product should be made mandatory or not. Our conclusions are presented in Sect. 6.

\section{Literature Review}

That younger persons are more environmentally concerned was conventional wisdom in the earliest years of research into consumption behaviour (Berkowitz and Lutterman 1968; Anderson and Cunningham 1972; Van Liere and Dunlap 1980). However, Laroche et al. (2001) proposed that there was a reversal in the early 1990s when older persons became more likely to show environmental concern. Xiao and McCright (2007) demured, maintaining that younger persons fit the profile of the green consumer better. Our own literature review finds no clear evidence that either conclusion is correct.

Part of the disparity in results lies with the way the issue is framed. Some studies separate the dependent variable into environmental knowledge, attitudes and behaviour; for example, Diamantopoulos et al. (2003). Their review uncovered only 2 out of 33 studies with significant relationships between age and environmental knowledge (both were negative). They concluded on this basis that there was no relationship between environmental knowledge and age. After their own data set was analysed, a negative albeit weak relationship was discovered, demonstrating that younger persons were slightly more likely to have greater environmental knowledge than older persons.

Diamantopoulos et al. (2003) predicted the correlation between environmental attitude and age would be negative, and their results supported this. The justification was based on Van Liere and Dunlap (1980) who argued that younger persons were more likely to embrace social change necessary for environmental protection, whereas older persons were more established in their habits and less malleable. However, as described by Diamantopoulos et al. (2003: p. 471):

\footnotetext{
[researchers have] often found that age is negatively related to (intended) behaviour, while those employing indicators of current behaviour have found that older people display higher levels of green behaviour... It is possible that such inconsistencies are due to a lack of resources among younger members of the population. Although younger people are likely to state that they will commit more resources to protecting the environment in the future... many do not currently have the financial security necessary to support environmental causes.
}

Jain and Kaur (2008) observed that while a few studies identify a non-significant relationship between pro-environmental consciousness and age (e.g. Kinnear et al. 1974; Meffert and Bruhn 1996; Roper 1992; Shrum et al. 1995), the majority of 
studies favour younger persons. Like Diamantopoulos et al. (2003), Jain and Kaur (2008) identified three outcome measures: environmental knowledge, attitude and behaviour. Their prediction was that the relationship between pro-environmental consciousness and age would yield results in favour of younger persons for all three categories. Their results only partly supported their prediction. Environmental attitude and environmental behaviour were both positively correlated with age (although only a weak relationship was found), and the relationship between environmental knowledge and age was not statistically significant.

Our own literature review suggests that reports on the relationship between age and pro-environmental consciousness are fairly evenly split between older and younger persons. From the 50 reviewed studies listed in Beer's Table 2.1, 11 found that older persons were more environmentally concerned, 14 determined younger persons, 3 found the middle age group the greenest, 16 studies gave results that were not significant and the remaining 6 studies did not test for age (Beer 2013). At the same time, in more recent years, there does seem to be some evidence of high levels of pro-environmental consumption in the midlife age group (see, e.g. Finisterra do Paço and Raposo 2010; Abeliotis et al. 2010).

In summary, despite the large number of enquiries, the evidence for a demographic bias in environmental awareness is mixed with no clear consensus as to whether it is the young, middle or older consumers who are more likely to express higher than average levels of environmental awareness. As a contribution to the debate, our paper applies a robust methodology to a unique data set and shows quite categorically that higher levels of environmental awareness are characteristic of the middle-aged consumer and, by extension, a relatively lower propensity of the young exhibit environmental awareness and pro-environmental behaviour often attributed to their age group.

\section{Data}

Identifying the relationship between age and levels of environmental awareness requires questions on knowledge of and attitudes towards the environmental consequences of product choice. Our analysis is based on a survey designed to elicit such information - the Flash Eurobarometer Survey - No. 256, 'Sustainable consumption and production', which was conducted in Europe in 2009. The survey was undertaken by the Gallup Organisation in 2009 on the request of the European Commission Directorate General Environment coordinated by EC Directorate General Communication (European Commission 2009). ${ }^{2}$

\footnotetext{
${ }^{2}$ The data were provided free on request from the GESIS (Leibniz Institute for the Social Sciences, Cologne) Archive Study (ID: ZA4983, Flash Eurobarometer 256, April 2009). See http:// www.gesis.org/eurobarometer/. The data set was provided on the understanding that neither the depositors, institutes nor GESIS bears any responsibility for the analysis or interpretation of the data.
} 
A sample of over 25,000 consumers was drawn from 28 countries - almost 1000 people in each. Telephone interviews were conducted between 21/04/2009 and 25/04/2009 by a range of different institutes who translated the original English questionnaire into their respective national language(s). ${ }^{3}$ The average length of interview was just over 9 min.

We selected four indicators of 'greenness' from the wider set of questions asked: how much people know about the products they buy, the importance they attach to their products' impact on the environment, the degree to which eco-labelling influenced their purchasing decision and finally how strongly they feel about mandatory carbon footprint labelling. Each of these four questions is reproduced in Appendix 1.

The distributions of responses over the four categories of each question are given in Table 1. For the purpose of this study, we collapse the responses to each question into binary responses. For example, in the case of product awareness, the majority of respondents said they know about the most significant impacts of the products they are purchasing although only 3533 of the 25,482 , or $14 \%$, believed they were fully aware. From the columns of Table 1a, we learn that up to $45 \%$ say they knew little or nothing about the environmental consequences of the products they were buying. The four rows are collapsed into the two columns in Table 1a, b.

Knowing about a products' impact and acknowledging its importance are two different things. Table $1 \mathrm{~b}$ shows that while about $(987+2915) / 25,206$ or $15.5 \%$ regarded the product's impact as not important, under half $(47.1 \%)$ viewed it as rather important, leaving only a third $(37.3 \%)$ who regard it as very important. It is this last group whose decisions we model below.

When it comes to measuring product awareness, there are mixed results. According to Table 1c more than half admitted that eco-labelling did not play an important part or they simply never read any labels. These three responses are collapsed into two. The first says that 'eco-labelling plays an important part in my purchasing decisions'. The rest says it does not play an important part or admit to not reading any labels. Over three quarters believed carbon footprint labelling should be mandatory (Table 1d). Only a small proportion, well under $10 \%$, said that the carbon footprint was not of interest.

In addition to our selection of these four questions about sustainable consumption, we also drew on the responses to the respondent's gender, age, years of

\footnotetext{
${ }^{3}$ In most EU countries and Croatia, the target sample size was 1000 respondents, except Malta, Cyprus and Luxembourg where the target size was 500 interviews. A weighting factor was applied to the national results in order to compute a marginal total where each country contributes to the European Union result in proportion to its population. These weights are not applied in our analysis so each country is weighted equally. A comparison of weighted and unweighted estimates in Appendix 2 shows that the differences in proportions are minimal, i.e. between 1 and $2 \%$. Furthermore the essential relationship between age and question responses is not sensitive to the presence of weighting even though the latter correctly adjusts for wider standard errors.
} 
Table 1 Indicators of sustainable consumption. The construction of binary variables from responses to four questions from the 'Sustainable consumption and production' Flash 256 European Commission Survey 2009

\begin{tabular}{|c|c|c|c|}
\hline \multicolumn{4}{|l|}{ A. Product awareness } \\
\hline \multirow{2}{*}{$\begin{array}{l}\text { Awareness about the environmental } \\
\text { impact of products bought or used }\end{array}$} & \multicolumn{2}{|c|}{ Awareness of the impact } & \multirow[b]{2}{*}{ Total } \\
\hline & Know little & Am aware & \\
\hline I know nothing & 2,117 & 0 & 2,117 \\
\hline I know little about this & 9,341 & 0 & 9,341 \\
\hline I know about the most significant impacts & 0 & 10,491 & 10,491 \\
\hline I am fully aware & 0 & 3,533 & 3,533 \\
\hline \multirow[t]{2}{*}{ Total } & 11,458 & 14,024 & 25,482 \\
\hline & 45 & 55 & $100 \%$ \\
\hline
\end{tabular}

B. Product importance

\begin{tabular}{l|r|c|c}
\hline \multirow{2}{*}{$\begin{array}{l}\text { Importance of the product's impact on the } \\
\text { environment when purchasing }\end{array}$} & \multicolumn{2}{|c|}{ Product's impact is very important } & \multirow{2}{*}{ Total } \\
\cline { 2 - 4 } & Not very important & Very Important & Torn \\
\hline Not at all important & 987 & 0 & 987 \\
\hline Rather not important & 2,915 & 0 & 2,915 \\
\hline Rather important & 11,880 & 0 & 11,880 \\
\hline Very important & 0 & 9,424 & 9,424 \\
\hline Total & 15,782 & 9,424 & 25,206 \\
\hline & 63 & 37 & $100 \%$ \\
\hline
\end{tabular}

C. Eco-labelling

\begin{tabular}{l|c|c|c}
\hline \multirow{2}{*}{$\begin{array}{l}\text { Some products have an eco-label which } \\
\text { certifies they are environmentally friendly }\end{array}$} & \multicolumn{2}{|l|}{ Importance of eco-labelling } & \multirow{2}{*}{ Total } \\
\cline { 2 - 3 } & Not very important & Important & 12,567 \\
\hline Eco-label plays a part & 0 & 12,567 & 6,112 \\
\hline Eco-label does not play a part & 6,112 & 0 & 6,611 \\
\hline I never read any label & 6,611 & 0 & 25,290 \\
\hline Total & 12,723 & 12,567 & $100 \%$ \\
\hline & 50 & 50 & \\
\hline
\end{tabular}

D. Carbon footprinting

\begin{tabular}{l|c|l|l}
\hline \multirow{2}{*}{$\begin{array}{l}\text { Should a label indicating the carbon } \\
\text { footprint of a product be mandatory in the } \\
\text { future }\end{array}$} & \multicolumn{2}{|l|}{ Importance of carbon footprint label } & \\
\cline { 2 - 4 } & Non-mandatory & Mandatory & Total \\
\hline Yes & 0 & 18,920 & 18,920 \\
\hline No, voluntary only & 3,620 & 0 & 3,620 \\
\hline Is of no interest & 1,855 & 0 & 1,855 \\
\hline Total & 5,475 & 18,920 & 24,395 \\
\hline & 22 & 18,920 & 24,395 \\
\hline
\end{tabular}

Source: Eurobarometer Flash Survey No. 256

Note: Percentage missing values, $0.81,1.88,1.56$ and 5.04, of full sample, respectively 
education and their occupational scale. ${ }^{4}$ Just under half the sample population were aged over 50 years, a quarter were below 38 and a quarter above 64 years. A surprising feature of the sample is that less than $40 \%$ of respondents were male $(37 \%)$. Just under half $(45.3 \%)$ recorded 15 years of education or less, $33.75 \%$ were still in education and $5.23 \%$ had between 16 and 22 years of study. When it came to occupation, as defined, half the sample of those 18 years and over were employed, the majority being in clerical, sales, etc. Of those outside the labour force, by far the largest proportion was retired. Settlements were broken down into three categories with nearly $20 \%$ defined as metropolitan; a further $44.5 \%$ were in the remaining town sizes leaving a third as rural.

In summary, we have at our disposal a very large sample of respondents from 28 countries across Europe who were interviewed in 2009. The four questions we selected tapped different aspects of the sustainability question: their awareness, the importance they attach to environmental impact and how they regard information tags such as eco-labelling and environmental footprints. The sample covers the full range of adult ages, but is somewhat light on male responses; otherwise, it captures the range of education levels, the occupations of the employed as well as the main activities of those not employed including those unemployed and those searching for work.

\section{Method}

Our aim is to assess the degree to which responses to the four environmental questions vary with age and in particular whether there is a significant difference between young, middle and older age groups. Since many other influences can moderate such attitudes, we control for gender, education, occupation, settlement size and country of residence.

We apply the following logistic model to the responses to each of the four questions on environmental impacts of consumption (awareness, importance, ecolabelling and carbon footprint). We refer to these responses quite generally as $\mathrm{E}$. Our primary or focal argument is the vector of 5 year age categories, A, to which we later add a set of covariates denoted by the vector $\mathrm{D}$. The responses are those of the $\mathrm{i}^{\text {th }}$ sampled individual:

$$
E_{i}=a_{o}+\beta_{i} A_{i}+\gamma_{i} D_{i}+\varepsilon_{i}
$$

Since $\mathrm{E}$ is binary $(1,0)$, the model is rendered linear model by taking the log odds of the event. The parameters $\beta_{i}$ and $\gamma_{i}$ capture the marginal impact of age and controls,

\footnotetext{
${ }^{4}$ Tabulations of responses over the categories of the variables are available on request. The categories themselves appear in Table 2 along with the regression results.
} 
respectively. Taking the exponent of the estimates of these parameters yields the odds ratios, $\mathrm{e}^{\beta \mathrm{i}}$ and $\mathrm{e}^{\lambda \mathrm{i}}$, which we report in our tabular results.

To aid communication we convert the odds ratios into probabilities using the following transformation:

$$
P_{i}=e^{a_{o}+\beta_{i} A_{i}+\gamma_{i} D_{i}} /\left(1+e^{a_{o}+\beta_{i} A_{i}+\gamma_{i} D_{i}}\right)
$$

where $P_{i}$ is the estimated probability of the event for the $i$ th respondent.

In summary, our aim is to understand the way responses to questions on sustainable consumption vary by age. Four logit models based on binary responses to each survey question are estimated as a function of age before and after controls. The pattern of estimated probabilities and their sensitivity to controls is used to identify the age groups most likely to consume in an environmentally sustainable manner.

\section{Results}

The results are presented in Fig. 1. Panel 1a illustrates the mean probability of being environmentally aware by 5 year age category, and panel 1c presents the age effects after the controls have been added. ${ }^{5}$ Panels $b$ and $d$ are explicit tests of the contrast between the predicted probabilities of awareness by age and the base age (the age with the highest level of awareness). The confidence intervals are used to judge whether the differences between the base maximum and its adjacent age groups are statistically significant Fig. 1.

The horizontal line running through panel a of Fig. 1 is the mean probability of awareness for the sample as a whole. It indicates that about half the population (0.545) are aware of the environmental impacts of the products they buy and use. The average probability of being aware rises from 0.438 among those under 20 year to a maximum average of almost $0.6(0.599)$ among the $40<45$ year age group. This level of awareness remains fairly stable over the middle age years through to 65 years $(0.558)$ after which it drops to its lowest point of 0.434 among those 80 years and over. The young and the old residents of Europe therefore report very similar low levels of environmental awareness.

We contrast the point estimates of the highest age group with the other age groups in turn. The result is shown graphically in panel b, Fig. 1 . The shaded $95 \%$ confidence band around the estimated means of Fig. 1a refers to the point estimates. They expand in size with the relative sample size of each age group. The age group with the maximum probability of being aware (the $40<45$ year age group) is the

\footnotetext{
${ }^{5}$ These graphs are generated using the marginsplot commands following logistic and margins in Stata 12. The survey (svy) function is used to generate the weighted results which are graphed in Appendix 2.
} 
a

Environmental awareness by age of consumer

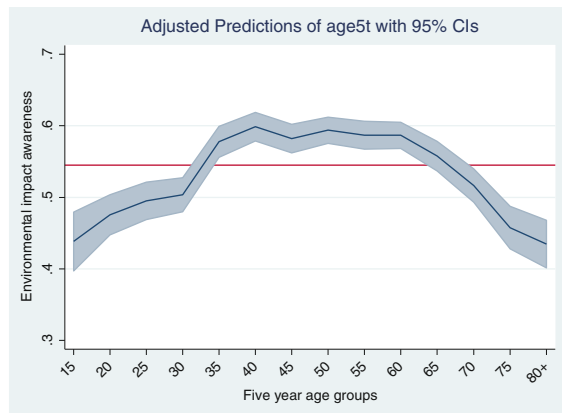

b

b Contrasts against age of maximum awareness

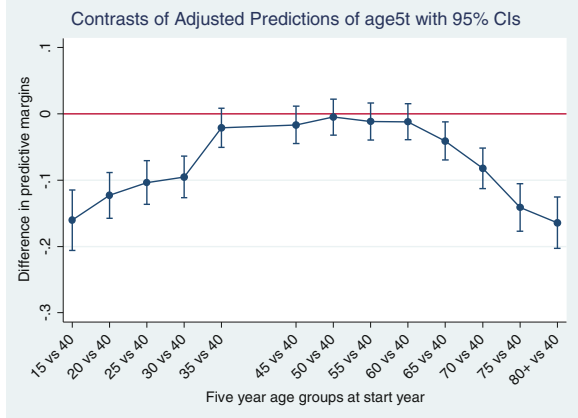

C Environmental awareness by age of consumer after controls

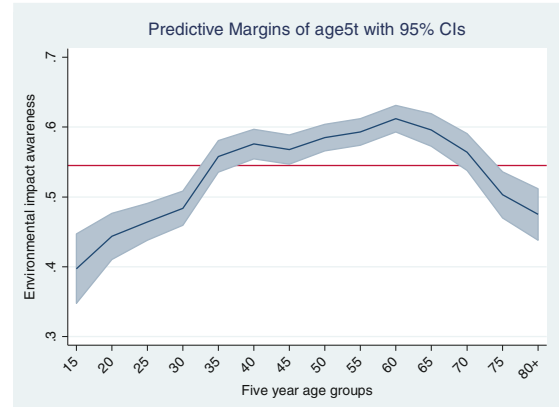

d Contrasts against age of maximum awareness after controls

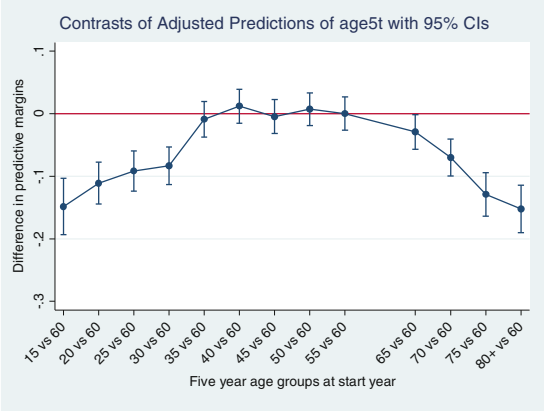

Fig. 1 Awareness of the environmental impact of consumer goods by age of consumer (Europe 2009)

line $0 .{ }^{6}$ An inspection of the confidence intervals around these contrasts shows no significant difference between the base and the three 5 year age intervals before and after the two 5 year age intervals that follow. In other words, there is a 30 year span of ages, from 35 to 64, over which mean levels of awareness of products' impact on the environment hardly vary. The distinction therefore is clearly between the middle-aged consumers on one hand and the young and old on the other hand. The maximum difference between the mean probability of awareness among the most and least aware age group is 0.165 .

Although it is common to use 'age' as an explanatory variable, in practice chronological age picks up different stages in the life course, such as periods when incomes are low and when they are high and when chances of unemployment are high and low, and so on. The variable 'age' therefore not only denotes chronological

\footnotetext{
${ }^{6}$ These marginsplot, contrast graphs, as drawn by Stata, designate the base by omitting it from the $\mathrm{X}$ label. Implicitly the base in panels $\mathrm{b}$ and $\mathrm{d}$ is zero as marked.
} 
age but also captures the life characteristics typically associated with a given age. In order to narrow the interpretation of a chronological age effect, we need to control for characteristics of the population associated with different life stages.

The results of applying Eq. (1) in its full form are reported in Table 2. Six models have been estimated beginning with model 1 which uses the age categories alone as arguments. The estimates from this regression are transformed via Eq. (2) to the predicted margins plotted in panel a of Fig. 1. While the table estimates are reproduced in the log-odds metric, the graphs are presented in the probability metric.

Moving across the columns in Table 2 from left to right allows us to monitor the effect of age on the odds of the positive binary response E. The 5 year age effects alone are presented in model 1 . The first control in model 2 shows the negative $(<1.0)$ effect of being a male on environmental awareness. It is negative but not significant. One might have expected that the proportion of women rising with age might have countered some of the negative effect of age on awareness, but the estimates in model 2 hardly change compared to model 1.

There are much clearer effects on age when the four education categories are added to the model, that is, when we move from model 2 to model 3 in Table 2. When the positive effects of years of education are added, the pseudo- $\mathrm{R}^{2}$ rises noticeably. 'Removing' the effect of years of education effectively decreases the differences in awareness between the young and middle age groups and noticeably reduces the gap between the middle and older consumers. However, adding the occupation, both inside and outside the labour force, returns the age categories to their pre-education effects, model 4 . Settlement is also added in model 5 but, apart from suggesting lower levels of awareness outside metropolitan centres, does not moderate the effects of age on environmental awareness.

Adding country dummies in model 6 has two primary influences. In cases where there are marked country differences, as in unemployment, for example, adding country fixed effects reduces the impact of variables like job seeking on awareness. On the other hand, the entry of country indicators increases the gap between the professions and other occupations, and it considerably increases the influence of the older middle age on environmental awareness. Other influences can also be read off from Table 2. ${ }^{7}$

Therefore, by the end of the first decade after the millennium, the age groups most aware of the environmental products they purchased were the middle aged a broad 30 year span of ages running from those in their mid-30s to their mid$60 \mathrm{~s}$. While the relative levels of awareness shifted within this age group, in terms of statistical significance there was little change. The net result of adding controls

\footnotetext{
${ }^{7}$ Corresponding tables for the remaining three responses are not reproduced here but are available on request.
} 
Table 2 Consumer awareness in Europe (2009) (odds ratios)

\begin{tabular}{|c|c|c|c|c|c|c|}
\hline Variable & Model 1 & Model 2 & Model 3 & Model 4 & Model 5 & Model 6 \\
\hline \multicolumn{7}{|l|}{ Age 5} \\
\hline 15 & (Base) & (Base) & (Base) & (Base) & (Base) & (Base) \\
\hline 20 & 1.16 & 1.16 & $1.24 *$ & 1.22 & 1.23 & 1.22 \\
\hline 25 & $1.26^{*}$ & $1.25^{*}$ & $1.37 * *$ & $1.31 *$ & $1.32 *$ & $1.34 *$ \\
\hline 30 & $1.3 * *$ & $1.3 * *$ & $1.45^{* *}$ & $1.39 * *$ & $1.41 * *$ & $1.46^{* *}$ \\
\hline 35 & $1.75^{* * *}$ & $1.75^{* *}$ & $2.01 * * *$ & $1.9 * * *$ & $1.9 * * *$ & $2.0 * * *$ \\
\hline 40 & $1.91 * * *$ & $1.91 * * *$ & $2.23 * * *$ & $2.1 * * *$ & $2.1 * * *$ & $2.16^{* * * *}$ \\
\hline 45 & $1.79 * * *$ & $1.78 * * *$ & $2.13 * * *$ & $1.99 * * *$ & $2.01 * * *$ & $2.09 * * *$ \\
\hline 50 & $1.87 * * *$ & $1.87 * * *$ & $2.29 * * *$ & $2.16 * * *$ & $2.19 * * *$ & $2.25 * * *$ \\
\hline 55 & $1.82 * * *$ & $1.82 * * *$ & $2.28 * * *$ & $2.18 * * *$ & $2.21 * * *$ & $2.33^{* * * *}$ \\
\hline 60 & $1.82 * * *$ & $1.81 * * *$ & $2.4 * * *$ & $2.29 * * *$ & $2.3 * * *$ & $2.54 * * *$ \\
\hline 65 & $1.62 * * *$ & $1.61 * * *$ & $2.15 * * *$ & $2.05 * * *$ & $2.07 * * *$ & $2.36^{* * * *}$ \\
\hline 70 & $1.37 * * *$ & $1.36^{* * *}$ & $1.9 * * *$ & $1.81 * * *$ & $1.84 * * *$ & $2.05^{* * *}$ \\
\hline 75 & 1.08 & 1.08 & $1.53 * * *$ & $1.45 * *$ & $1.47 * *$ & $1.58^{* *}$ \\
\hline $80+$ & 0.984 & 0.981 & $1.43^{* * *}$ & $1.36^{*}$ & $1.36^{*}$ & $1.4^{*}$ \\
\hline \multicolumn{7}{|l|}{ Male } \\
\hline Female & & (Base) & (Base) & (Base) & (Base) & (Base) \\
\hline Male & & 0.98 & $0.948^{*}$ & $0.929 * *$ & $0.926 * *$ & $0.928 * *$ \\
\hline
\end{tabular}

\section{Education}

\begin{tabular}{l|l|l|l|l|l}
\hline No education & & (Base) & (Base) & (Base) & $($ Base $)$ \\
\hline Up to 15 years & & $1.57^{* * *}$ & $1.53^{* * *}$ & $1.52^{* * *}$ & $1.47 * * *$ \\
\hline $16<=20$ years & & $2.29 * * *$ & $2.02 * * *$ & $2 * * *$ & $2.1 * * *$ \\
\hline Still in education & & $2.4 * * *$ & $2.14 * * *$ & $2.12^{* * *}$ & $2.21 * * *$ \\
\hline
\end{tabular}

\section{Occupation}

\begin{tabular}{|c|c|c|c|}
\hline Prof and man & (Base) & (Base) & (Base) \\
\hline Middle man & 0.901 & 0.904 & $0.846^{* * * *}$ \\
\hline Clerical, sale & $0.752 * * *$ & $0.754 * * *$ & $0.711 * * *$ \\
\hline Manual & $0.569 * * *$ & $572 * * *$ & $0.531 * * *$ \\
\hline Homemaker & $0.632 * * *$ & $0.637 * * *$ & $0.565 * * *$ \\
\hline Student & 0.789 & 0.793 & $0.74 *$ \\
\hline Retired & $0.748 * * *$ & $0.751 * * *$ & $0.627 * * *$ \\
\hline Seeking job & $0.748 * * *$ & $0.751 * * *$ & $0.627 * * *$ \\
\hline \multicolumn{4}{|l|}{ Settlement } \\
\hline Metropolitan & & (Base) & (Base) \\
\hline Urban/town & & 0.942 & 0.931 \\
\hline Rural & & 0.959 & $0.85 * * *$ \\
\hline \multicolumn{4}{|l|}{ Country } \\
\hline France & & & (Base) \\
\hline Belgium & & & $0.41 * * *$ \\
\hline Netherlands & & & $0.323 * * *$ \\
\hline Germany & & & $0.376^{* * *}$ \\
\hline
\end{tabular}


Table 2 (continued)

\begin{tabular}{|c|c|c|c|c|c|c|}
\hline Variable & Model 1 & Model 2 & Model 3 & Model 4 & Model 5 & Model 6 \\
\hline Italy & & & & & & $0.417 * * *$ \\
\hline Luxembourg & & & & & & $0.588 * * *$ \\
\hline Denmark & & & & & & $0.18 * * *$ \\
\hline Ireland & & & & & & $0.222 * * *$ \\
\hline UK & & & & & & $0.274 * * *$ \\
\hline Greece & & & & & & $0.267 * * *$ \\
\hline Spain & & & & & & $0.247 * * *$ \\
\hline Portugal & & & & & & $0.292 * * *$ \\
\hline Finland & & & & & & $0.189 * * *$ \\
\hline Sweden & & & & & & $0.228 * * *$ \\
\hline Austria & & & & & & $0.535^{* * *}$ \\
\hline Cyprus & & & & & & $0.173^{* * *}$ \\
\hline Czech Republic & & & & & & $0.336^{* * *}$ \\
\hline Estonia & & & & & & $0.218 * * *$ \\
\hline Hungary & & & & & & $0.335^{* * *}$ \\
\hline Latvia & & & & & & $0.259 * * *$ \\
\hline Lithuania & & & & & & $0.222 * * *$ \\
\hline Malta & & & & & & $0.64 * * *$ \\
\hline Poland & & & & & & $0.451 * * *$ \\
\hline Slovakia & & & & & & $0.348 * * *$ \\
\hline Slovenia & & & & & & $0.537 * * *$ \\
\hline Bulgaria & & & & & & $0.175^{* * *}$ \\
\hline Romania & & & & & & $0.309 * * *$ \\
\hline Croatia & & & & & & $0.284 * * *$ \\
\hline _cons & $0.78 * *$ & $0.788^{* *}$ & $0.38 * * *$ & $0.563 * * *$ & $0.586 * * *$ & $2.06 * * *$ \\
\hline r2_p & 0.00761 & 0.00763 & 0.0222 & 0.0255 & 0.0255 & 0.0508 \\
\hline $\mathrm{N}$ & 25,482 & 25,482 & 25,160 & 25,160 & 25,050 & 25,050 \\
\hline 11 & $-17,400$ & $-17,400$ & $-16,919$ & $-16,861$ & $-16,787$ & $-16,350$ \\
\hline chi2 & 267 & 268 & 768 & 883 & 877 & 1,751 \\
\hline
\end{tabular}

Source: Eurobarometer Flash Survey No. 256

Note: Sample sizes vary in response to missing values on some variables: 25,482 to 25,050 . While this $1.69 \%$ decline is unlikely to influence the coefficients greatly, we did rerun the six models using just the sample set used to construct model 6. A comparison of the results confirmed the stability of the odds ratios as none varied by more than 0.005 .

$* p<0.05, * * p<0.01$ and $* * * p<0.001$

on the age effects is threefold: the first is to widen the gap between the younger and middle age groups (as shown in panel c of Fig. 1). The second is to decrease the distance to the awareness of the older respondents, and the third is to raise the apparent level of awareness of those in their 50s and 60s causing a net shift of the plot upward to the right (compare panel a with $\mathrm{c}$ in Fig. 1). 
We turn now to the second question asked of consumers, namely, the importance they attach to the product's impact on the environment. Just over one third of the sample assigned importance to the environmental impact of the purchases they made (mean $=0.374$ ). In the uncontrolled case, the probability of recognising the imbalance of environmental impact rises steadily with age, reaching a maximum among those in their early 70 s; see Fig. 2, panel a. ${ }^{8}$

Unlike Fig. 1, including covariates made remarkably little difference to the way responses to the important question varied by age. In Fig. 2 only the increased negative effect of being male stood out. There was virtually no difference between the age effects of panels $a$ and $c$ (and hence $b$ and $d$ ). An inspection of the

a Environmental awareness by age of consumer

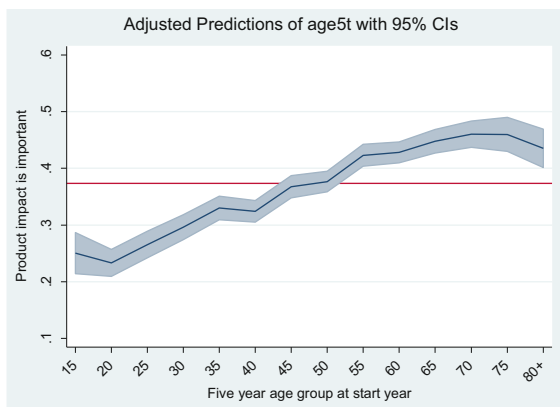

b Contrasts against age of maximum awareness

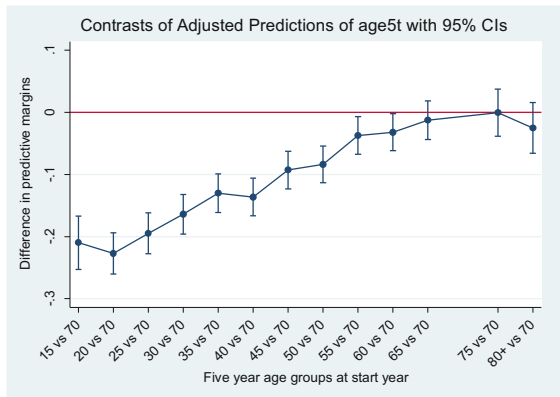

C Environmental awareness by age of consumer after controls

Predictive Margins of age $5 \mathrm{t}$ with $95 \% \mathrm{Cls}$

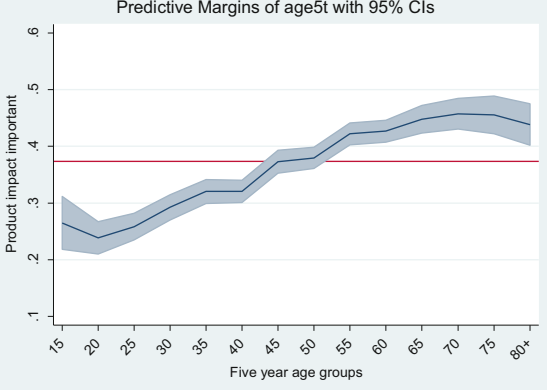

d Contrasts against age of maximum awareness after controls

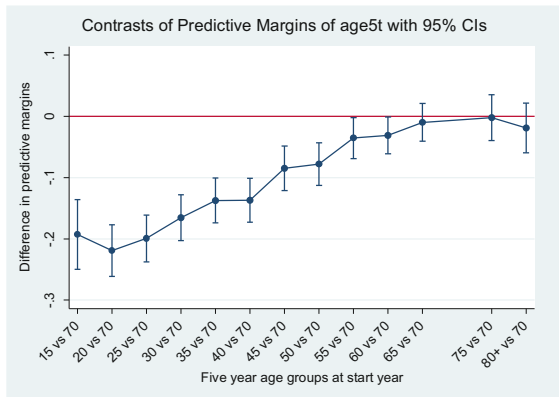

Fig. 2 The probability of regarding product impact on the environment as important (Europe 2009)

\footnotetext{
${ }^{8}$ It may appear that when it comes to assigning importance, it is no longer those under 20 who are the least engaged; rather it is those in their early 20s. However this difference is not statistically significant.
} 
a

Environmental awareness by age of consumer

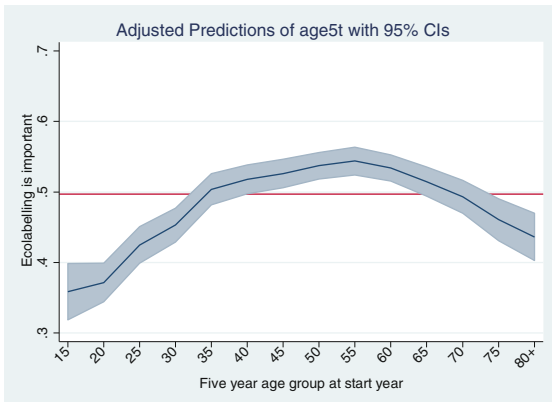

b

Contrasts against age of maximum awareness

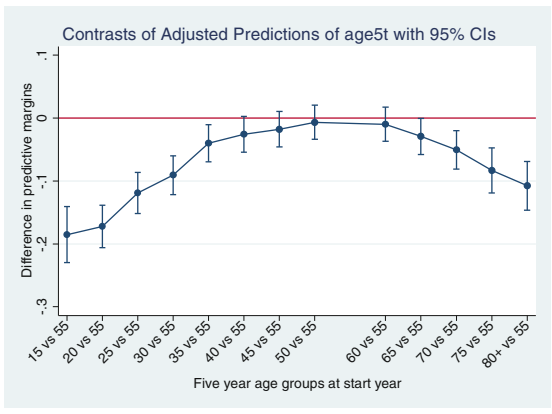

C Environmental awareness by age of consumer after controls

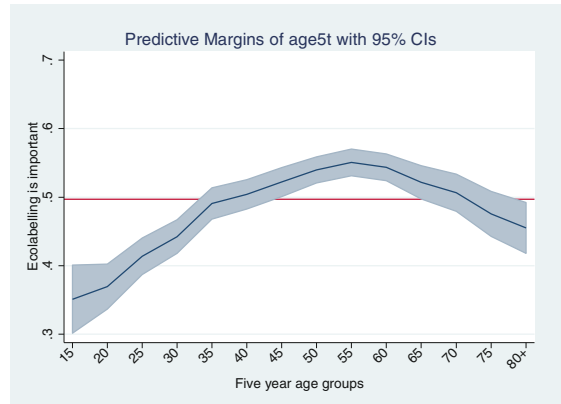

\section{d} after controls

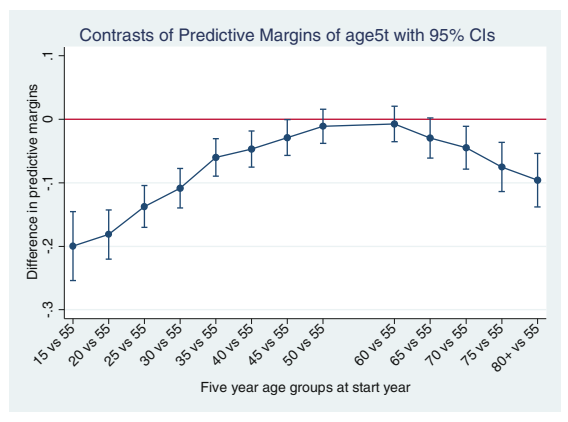

Fig. 3 The probability that eco-labelling plays an important part in the purchasing decision (Europe 2009)

corresponding estimate table (available on request) shows a markedly reduced effect of education and occupational differences when it came to attaching importance to environmental effects, as opposed to simply being aware of them. Similarly with country fixed effects, while marked contrasts between countries remain, numerically there were relatively fewer.

When it comes to the role eco-labelling plays in purchase decisions, almost half the sample said eco-labelling played an important part in their purchasing decisions (0.497) as shown in Fig. 3, panels a and c. The strong inverse U shape apparent in Fig. 1 reappears here in Fig. 3 as well. Eco-labelling is most likely to assume importance among the older middle aged, those in their $55<60$ age group, and this positioning remained even after controls were entered. The only shift we see in the age profile occurs at the far right of the graph where controls diminish the negative effect of those in their 70s and 80s. Over most of the age distribution, controls made remarkably little difference to the way the importance of eco-labelling varied with age. 
a Environmental awareness by age of consumer

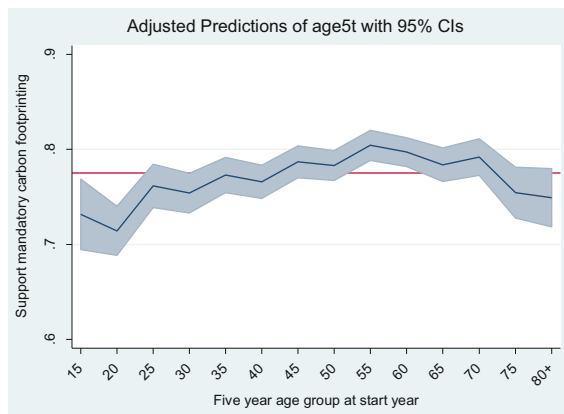

b Contrasts against age of maximum awareness

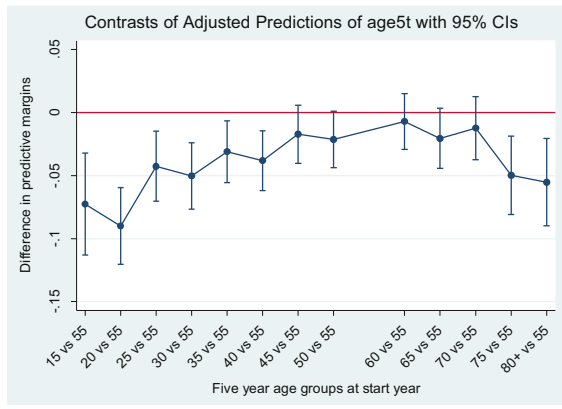

C Environmental awareness by age of consumer after controls

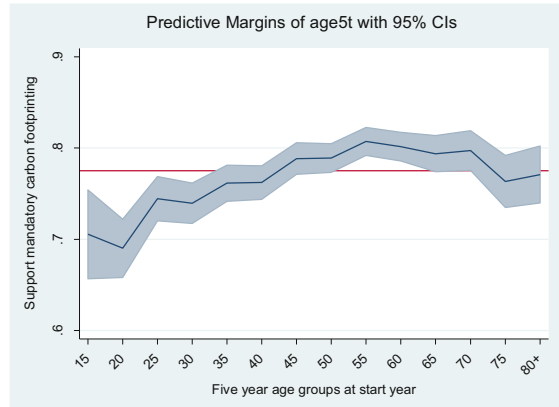

d Contrasts against age of maximum awareness after controls

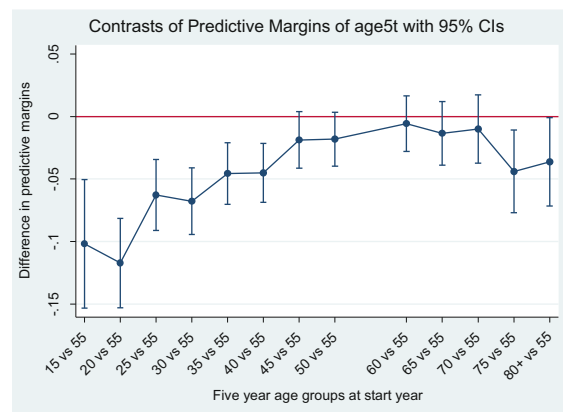

Fig. 4 The probability that consumers believe carbon footprint labelling should be mandatory (Europe 2009)

The final question we examine is whether eco-labelling should be mandatory or not. In this case over three quarters of the consumers believed products should carry a label showing its carbon footprint (0.776). While the age profile took a similar shape to that of the previous question, in Fig. 4 the differences between young, middle and older consumers were noticeably less marked, the range of average responses falling within the $0.7-0.8$ range across the age groups. The most likely to favour mandatory carbon footprint labelling were those $55<60$ years, but there was no significant difference over the age span 45 through 70 years (as the difference in predictive margins shows, panel $4 b$ ).

The age profile remains largely intact when we enter controls, as a comparison of panels $4 \mathrm{a}$ and $4 \mathrm{c}$ shows. Comparing the predictive margins, $4 \mathrm{~b}$ with $4 \mathrm{~d}$ highlights the differences. The primary effect of controls is to lower the relative support for carbon labelling among the young. Inspection of the estimate table (not shown) reveals that 
the primary reason for this and the enhanced support at the oldest ages is the entry of country dummy variables. In other words, differences between countries tend to disguise the relatively much lower support the young offer mandatory carbon footprint labelling.

In summary, there is considerable empirical support in the Eurobarometer survey for 'middle-aged greenness' - the propensity of those in their 40s through 60s to exhibit the knowledge, purchasing behaviour and support for measures designed to encourage environmentally sustainable consumption. Although the actual age profiles in Figs. 1, 2, 3 and 4 differ slightly depending on the question asked, there remains a clear distinction between the responses of the young, middle- and olderaged consumers in each case.

\section{Conclusions}

Many people automatically assume that it will be the young who are most environmentally aware in part because the young grew up in an era of greater environmental consciousness. However our review of the literature revealed a distinct lack of consensus among scholars on how age effects pro-environmental consumption.

We began our study with no a priori assumption of the relationship between age and pro-environmental attitudes but soon uncovered a consistent peaking of pro-environmental attitudes among the middle-aged brackets - those in their 40s, 50s and 60s. The inverse U-shaped relationship we found between age and environmental consciousness held even after controlling for a range of other possible influences: gender, education occupation, settlement size and country of residence.

Of the four questions about environmental impact, we found that only one experienced a change in the age profile after controls were added - the level of knowledge consumers had about the environmental impact of the products they bought and consumed. Controlling for attributes that change with age raised the average age at which such awareness peaked, as well as lowering the relative level of awareness of the very young and reducing the effect of old age on awareness.

Our results on age are consistent with those of Laroche et al. (2001) who commented that prior to the early 1990s, it was common to find younger persons as being more environmentally concerned, but that this tendency has been reversed in the last two decades.

There are two theories that might explain the empirical support we find for the pro-environmental middle aged consumer. The first is that we are seeing a cohort effect (Samdhal and Robertson 1989; Gilg et al. 2005; Straughan and Roberts 1999; Roberts 1996b). The alternative is that the high level of pro-environmental 
consciousness we are witnessing in the middle-aged years reflects a life-stage age effect (Dychtwald and Gable 1990). The distinction is important because the former implies only a temporary shift in the age of the highest consciousness, whereas the latter implies persistence of the inverse $U$ distribution over time. Further research on longitudinal or panel data would help discriminate between these two possibilities.

Of particular interest in this volume in honour of Professor Higano is the degree to which the relative importance of the arguments raised in the European case hold elsewhere. In Asia there is a concern that consumer's awareness of environmental degradation is still rather low despite high education levels (Chan 2000). Only a handful of studies have compared environmental attitudes across countries (Schultz and Zelezny 1999; Zelezny et al. 2000; Inglehart 1995; Alibeli and Johnson 2009; National Geographic 2010). Therefore and we support Schultz and Zelezny who '.... believe that a multinational understanding of the values and motives that underlie environmental concern and behavior is needed before we can move toward more effective environmental policies and social interventions designed to increase pro-environmental behavior' (1999: 264).

This same heterogeneity is likely to prevail across Asia, but we do not yet know the degree to which pro-environmental attitudes of Asian consumers will exhibit the same middle-aged bias that our European sample has revealed. This remains an intriguing question which a regional scientist may wish to explore.

Acknowledgements The literature review and initial empirical analysis were undertaken by Ben Beer of partial fulfilment of requirements for the Masters of Environmental Studies 90 point thesis presented to Victoria University of Wellington (Beer 2013). Ben Beer's supervisor, Professor Philip Morrison, reanalysed the data sometime later and drafted the chapter. Both authors acknowledge the use of the survey European Commission (2009). See http://ec.europa.eu/public_opinion/flash/ fl_256_en.pdf.

\section{Appendix 1: Survey Questions Analysed}

These four questions constitute the dependent variables which relate to environmental consciousness and are listed as follows (as well as response options):

Question 1: In general, how much do you know about the environmental impact of the products you buy and use?

\begin{tabular}{l|l}
\hline I am fully & 4 \\
\hline I know about the most significant impacts & 3 \\
\hline I know little about & 2 \\
\hline I know nothing & 1
\end{tabular}


Question 2: How important are the following aspects when making a decision on what products to buy? (a) The product's impact on the environment:

\begin{tabular}{l|l}
\hline Very important & 4 \\
\hline Rather important & 3 \\
\hline Rather not important & 2 \\
\hline Not at all important & 1 \\
\hline
\end{tabular}

Question 3: Some products have an eco-label which certifies that they are environmentally friendly. Which statement characterises you the best?

\begin{tabular}{l|l}
\hline Eco-labelling plays an important part in my purchasing decisions & 1 \\
\hline Eco-labelling does not play an important part in my purchasing decisions & 2 \\
\hline I never read any labels & 3 \\
\hline
\end{tabular}

Question 5: Should a label indicating the carbon footprint of a product be mandatory in the future?

\begin{tabular}{l|l}
\hline Yes & 1 \\
\hline No, it should be done on a voluntary basis & 2 \\
\hline The carbon footprint is of no interest to me & 3 \\
\hline
\end{tabular}

Source: Flash Eurobarometer Survey No. 256

\section{Appendix 2: A Note on Weighting}

The analysis in this paper has been undertaken without weighting. While there are subtle differences in the results with and without the survey's recommended weighting, the results at the level we are interested in remain essentially the same. We demonstrate this by rerunning the results in Fig. 1 as Fig. 5 here. The primary difference of course is the higher standard errors which are reflected here in the wider confidence intervals when comparing Fig. 5 to Fig. 1. There is also a one category shift to the right in age in this particular instance. However the essential difference between the young, middle and old remains the same.

The contrasts yield almost identical results as a comparison of Fig. $5 \mathrm{~b}$ with Fig. 1b shows. Similar results hold for the weighted and unweighted cases after the addition of controls; compare Fig. 5c with Fig. 1c and Fig. 5d with Fig. 1d. 


\section{a Environmental awareness by age of} consumer

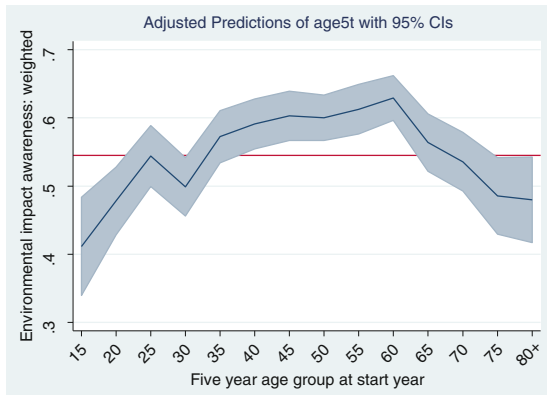

\section{b Contrasts against age of maximum awareness}

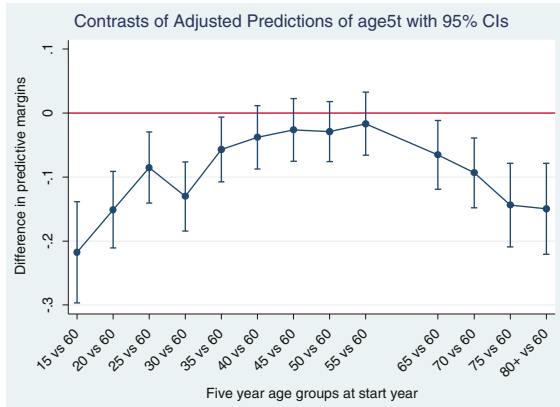

C

\section{Environmental awareness by age of consumer after controls}

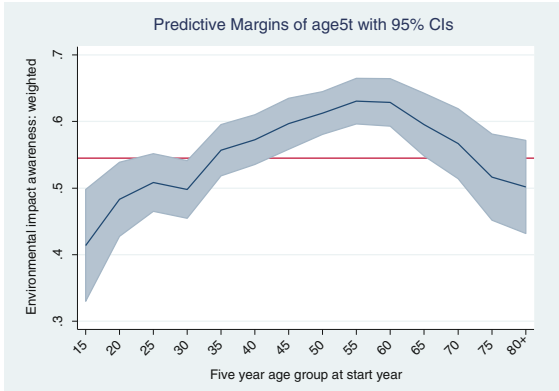

d

d Contrasts against age of maximum awareness after controls

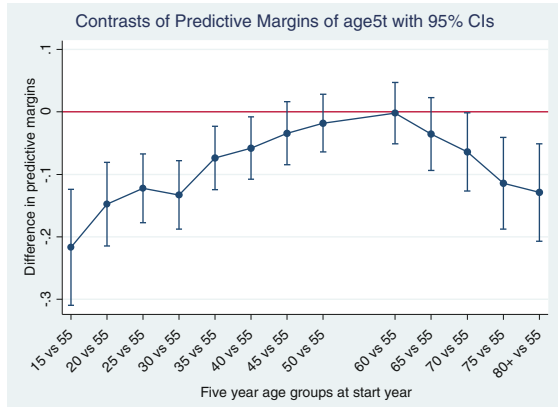

Fig. 5 Awareness of the environmental impact of consumer goods by age of consumer (Europe 2009)

\section{References}

Abeliotis K, Koniari C, Sardianou E (2010) The profile of the green consumer in Greece. Int J Consum Stud 34:153-160

Alibeli N, Johnson C (2009) Environmental concern: a cross national analysis. J Int Cross-Cult Stud 3(1): 1-10

Anderson WT Jr, Cunningham WHC (1972) The socially conscious consumer. J Mark 36(3):23-31

Arcury TA, Christianson EH (1990) Environmental worldview in response to environmental problems: Kentucky 1984 and 1988 compared. Environ Behav 22:387-407

Balderjahn I (1988) Personality variables and environmental attitudes as predictors of ecologically responsible consumption patterns. J Bus Res 17:51-56

Beer B (2013) 'Mid-life greenness'. Environmental consciousness among European consumers (Masters of Environmental Studies). Victoria University of Wellington, Wellington

Berkowitz L, Lutterman KG (1968) The traditional socially responsible personality. Public Opin Q 32:169-185

Bodur M, Sarigollu E (2005) Environmental sensitivity in a developing country: consumer classification and implications. Environ Behav 37(4):487-510 
Carlisle S, Hanlon P (2007) Well-being and consumer culture: a different kind of public health problem? Health Promot Int 22(3):261-268

Chan K (2000) Market segmentation of green consumers in Hong Kong. J Int Consum Mark 12(2):7-24

Datta S (2011) Pro-environmental concern influencing green buying: a study on Indian consumers. Int J Bus Manag 6(6):124-133

Diamantopoulos A, Schlegelmilch B, Sinkovics R, Bohlen G (2003) Can socio-demographics still play a role in profiling green consumers? A review of the evidence and an empirical investigation. J Bus Res 56:465-480

D'Souza C, Taghian M, Lamb P, Peretiatko R (2007) Green decisions: demographics and consumer understanding of environmental labels. Int J Consum Stud 31:371-376

Dychtwald K, Gable G (1990) Portrait of a changing consumer. Bus Horiz 33(1):62-73

European Commission (2009) European's attitude towards the issue of sustainable consumption and production. Analytical report. The Gallup Organisation, Hungary

Finisterra do Paco A, Raposo M (2010) Green consumer market segmentation: empirical findings from Portugal. Int J Consum Stud 34:429-436

Gilg S, Barr N, Ford N (2005) Green consumption or sustainable lifestyles? Identifying the sustainable consumer. Futures 37:481-504

Inglehart R (1995) Public support for environmental protection: objective problems and subjective values in 43 societies. Polit Sci Polit 28(1):57-72

Jain S.K., Kaur G (2004) Green marketing: an attitudinal and behavioural analysis of Indian consumers. Glob Bus Rev 5(2):187-205

Jain S.K., Kaur G (2008) Role of socio-demographics in segmenting and profiling green consumers. J Int Consum Mark 18(3):107-146

Kinnear T, Taylor J, Ahmed S (1974) Ecologically concerned consumers: who are they? J Mark 38(2):20-24

Laroche M, Bergeron J, Barbaro-Forleo G (2001) Targeting consumers who are willing to pay more for environmentally friendly products. J Consum Mark 18:503-520

Meffert H, Bruhn M (1996) Das Umweltbewußtsein von Konsumenten. Die Betriebswirtsch 56(5):621-648

National Geographic (2011) Greendex 2010: Consumer Choice and the Environment-A Worldwide Tracking Survey. http://environment.nationalgeographic.com/environment/greendex/ [Accessed 11 Dec 2011]

Peattie K (2001) Golden goose or wild goose? The hunt for the green consumer. Bus Strategy Environ 10:187-199

Pepper M, Jackson T, Uzzell D (2009) An examination of the values that motivate socially conscious and frugal consumer behaviours. Int J Consum Stud 33:126-136

Roberts JA (1996) Green consumers in the 1990s: profile and implications for advertising. J Bus Res 36(3):217-231

Robins N (1999) Making sustainability bite: transforming global consumption patterns. J Sustain Prod Des 10:7-16

Roos A, Nryud A (2008) Description of green versus environmentally indifferent consumers of wood products in Scandinavia: flooring and decking. J Wood Sci 54(5):402-407

Roper Organisation 1992 Environmental behaviour. North American: Canada, Mexico, United States Commissioned by S.C.Johnson and Son Ltd

Samdahl M, Robertson R (1989) Social determinants of environmental concern: specification and test of the model. Environ Behav 21(1):57-81

Saphores J, Nixon H, Ogunseitanc O, Shapirod A (2007) California households' willingness to pay for "Green" electronics. J Environ Plan Manag 50(1):113-133

Schaefer A, Crane A (2005) Addressing sustainability and consumption. J Macromark 25:76-92

Schor J (2005) Prices and quantities: unsustainable consumption and the global economy. Ecol Econ 55:309-320

Schultz P, Zelezny L (1999) Values as predictors of environmental attitudes: evidence for consistency across 14 countries. J Environ Psychol 19:255-265 
Scott D, Willits K (1994) Environmental attitudes and behavior: a Pennsylvania survey. Environ Behav 26(2):239-260

Shrum L, McCarty J, Lowrey T (1995) Buyer characteristics of the green consumer and their implications for advertising strategy. J Advert 24(2):71-82

Sinnappan P, Rahman A (2011) Antecedents of green purchasing behavior among Malaysian consumers. Int Bus Manag 5(3):129-139

Soron D (2010) Sustainability self-identity and the sociology of consumption. Sustain Dev 18:172-181

Straughan R, Roberts J (1999) Environmental segmentation alternatives: a look at green consumer behavior in the new millennium. J Consum Mark 16(6):531-575

Tognacci N, Weigel R, Wideen F, Vernon D (1972) Environmental quality: how universal is public concern? Environ Behav 4(1):73-86

Van Liere K, Dunlap R (1980) Environmental concern: does it make a difference? How it is measured? Environ Behav 13(6):651-76

Webster E (1975) Determining the characteristics of the socially conscious consumer. J Consum Res 2:188-196

Xiao C, McCright A (2007) Environmental concern and sociodemographic variables: a study of statistical models. J Environ Educ 38(2):3-14

Zarnikau J (2003) Consumer demand for 'Green Power' and energy efficiency. Energy Policy 31:1661-1672

Zelezny L, Chua P, Aldrich C (2000) Elaborating on gender differences in environmentalism. J Soc Issues 56(3):443-457

Zimmer M, Stafford T, Stafford M (1994) Green issues: dimensions of environmental concern. J Bus Res 30(1):63-74 